\title{
EXPERIMENTAL AND MODELING OF FLOW OVER LABYRINTH AND PLAIN STEPPED FALLS
}

\author{
SHAKER A. JALIL and BSHKOJ S. HUSSEIN \\ Dept. of Water Resource Engineering, College of Engineering, University of Duhok, Kurdistan Region-Iraq
}

\begin{abstract}
The characteristics of flow over plain and labyrinth stepped falls is investigated experimentally and simulated numerically using commercial package ANSYS CFX. The aim is to verify the numerical model by assessing its accuracy and dependence in modeling the flow over this kind of hydraulic structures. Eight physical models of rectangular labyrinth stepped fall cycles with general slope (1V:1H and 1V:2H), different step numbers (5 and 10) and two different cycle widths $(0.06$ and $0.1 \mathrm{~m})$ were tested and simulated in laboratory flume. For the purpose of comparison four models of plain stepped falls are constructed with the same number of steps and slopes as the labyrinth ones, they were tested and simulated. The simulation is based on the RNG k- $\varepsilon$ turbulence model, three dimensional volume of fluid method (VOF) and incompressible flows. To verify the numerical models, all experimental data including water surface profile, hydraulic head and total calculated energy dissipation were compared with the corresponding results predicted by the numerical model. The comparison showed good agreement between experimental and numerical results via applying statistical tests. The new labyrinth stepped fall model was more effective for dissipating the relative energy as compared with plain stepped falls. The results showed that with decreasing number of steps, downstream slope and increasing the length magnification ratio, the relative energy dissipation is increased. The numerical results illustrated that the local direction of flow depends on the depth of water on the steps and the width of the labyrinth cycle. Also it was observed that the local flow directions, which are occurred on streamlines and contours, are dependent on impingement angle of water velocity vectors which varies between 74 and 62.5 degree.
\end{abstract}

KEYWORDS: Ansys CFX, Energy dissipation, Labyrinth stepped falls, Plain stepped falls, RNG $k-\varepsilon$ turbulence model, VOF model

\section{INTRODUCTION}

Stepped falls are one of the good hydraulic structures which have significant effect on energy dissipation due to its rough surface. Stepped falls designed to release overflowing water. Nowadays, with the availability of commercial CFD codes and high-performance digital computers, the hydraulic characteristics of flow can be quickly estimated. In general CFD can provide a fast solution and reduces the cost of production compared with the experimental model. The three dimensional computational fluid dynamic with the turbulence model can help to understand and analyze the characteristic complexity and rapidity changes of the flow. Chenet et al. (2002) finds that the mean minimum pressure on the surface of the step is important to assess the risk of cavitation, and the volume of fluid method with $k-\varepsilon$ turbulence model has significant advantages for simulation. The nappe flow regime in the stepped spillways has been studied by Jahromi et al. (2008) by physical and numerical models. The energy dissipation of two slopes $\left(15^{\circ}\right.$ and $\left.25^{\circ}\right)$ with number of steps $(5,10$, 15 and 30 steps) each slope shows the nearly same results with percentage error less than $6 \%$. The result of investigation on hydraulic jumps occurs on steps with baffles and sills in each step show also good agreement between physical and numerical of RNG k- $\varepsilon$ turbulence models, this finding is noted by Carvalho and Martins (2009). The same agreement is achieved by Rad and Teimouri (2010) in investigating energy dissipation on simple stepped spillways based on (Salmasi 2003) experiments and by employing standard $\mathrm{k}-\varepsilon$ model and volume of fluid model (VOF). Taghizadehet et al. (2012) used RNG k-E turbulence models of numerical Flow 3D computational fluid dynamic software to investigate pressure fluctuations for stepped threeside spillway. The experimental findings of Jareh Dam's spillway were used for the purpose of verification to show that the numerical model using 3D Flow code was capable of simulating the free surface flow in the side channel. In addition, 
it was concluded that stepped three-side spillway gave an important role in reducing cavitation and negative pressure. Kositgittiwong (2012) used Fluent CFD code with different turbulence models, $\mathrm{k}-\varepsilon$ standard, RNG $\mathrm{k}-\varepsilon, \mathrm{k}-\varepsilon$ Renormalization group, $\mathrm{k}-\omega$ standard, and shear stress transport $\mathrm{k}-\omega$ model to simulate energy losses, velocity profile and the behavior of flow on a step for smooth and stepped spillway. The verification of Kositgittiwong based on (Ward 2002) experiential results. Kositgittiwong showed good agreement between experimental and numerical models and the stepped spillway was more efficient in energy dissipation than the smooth spillway. Shoja et al. (2013) studied energy dissipation in stepped spillway using Fluent software via finite element and finite volume methods. The investigation used experimental results of (Chanson and Toombes 2001) to calibrate the numerical models. The relative error percentages for calculated energy dissipation using finite element and finite volume methods were $2.85 \%$ and $1.26 \%$ respectively. Jorabloo and Fuladipanah (2013) find that Fluent CFD code is helpful for simulating flow in hydraulic constructions, and good for estimating energy dissipation in stepped spillway. The effect of number of steps and slope on energy losses in Siahbisheh dam spillway has been simulated by Bazargan and Safakheil (2013), the finding is that energy losses decreases with the increase of discharge. Karamiet et al. (2014) studied cavitation phenomenon on dam stepped spillway numerically using (Flow-3D) code. The study shows that that the simulation of dam stepped spillway release is useful for controlling the damage of cavitation by increasing the cavitation index and reducing the discharge. Ameen (2014) used Flow 3D software by employing k- $\varepsilon$ turbulence model to simulate flow passing over plain stepped spillway. The verification based on four stepped physical models to estimate energy dissipation which is within the acceptable error. The maximum error was $11.13 \%$. Then Ameen forwarded an empirical equation for estimating the percent of energy dissipation. This equation reflects the outputs of the simulations on twenty seven numerical models. Husain et al. (2014) used smooth particle hydrodynamics (SPH) code to investigate the pressure distribution on horizontal and vertical faces of stepped spillway. Also the location of minimum and maximum pressure values was obtained. In the present study, a commercial CFD code (ANSYS CFX) was used to verify flow phenomena over two different types of stepped falls, the first has plain steps while the second has labyrinth steps. The labyrinth stepped fall has some steps of longer length than ordinary stepped fall and also has wider effective width. The verification of the numerical models is based on experimental results of water surface, pressure measurements and relative energy dissipation. The simulation models extend the understanding of flow phenomena over plain and labyrinth stepped fall cycles and makes the flow behavior clearer.

\section{GOVERNING EQUATIONS}

The Reynolds Averaged Navier-Stokes (RANS) were used in the numerical model which based on the finite volume technique discretization method. These equations satisfy the time averaged conservation equations (continuity and momentum) for the fluid (ANSYS-CFX help 2014).

The mass and momentum conservation equations for an incompressible flow solved by the ANSYS$\mathrm{CFX}$ are expressed (in tensor form) (Piradeepan, 2002):

Mass conservation equation

$\frac{\partial \rho}{\partial t}+\frac{\partial}{\partial x_{i}}\left(\rho U_{i}\right)=0$

Momentum conservation equation

$$
\frac{\partial\left(\rho U_{i}\right)}{\partial t}+\frac{\partial}{\partial x_{j}}\left(\rho U_{i} U_{j}\right)=-\frac{\partial P}{\partial x_{i}}+\frac{\partial}{\partial x_{j}}\left[\mu\left(\frac{\partial U_{i}}{\partial x_{j}}+\frac{\partial U_{j}}{\partial x_{i}}\right)\right]+\frac{\partial}{\partial x_{j}}\left(-\rho \overline{\hat{u}_{\imath} \dot{u}_{j}}\right)
$$

where,

$\rho=$ The density of fluid, $t=$ time, $x=$ axis coordinates, $P=$ mean pressure,

$U_{i}=$ mean component of velocity, $\mu=$ dynamic viscosity and $\dot{u}_{i}=$ fluctuating part of the velocity.

The term $\left(\frac{-\partial\left(\rho \overline{u_{l} \dot{u}_{j}}\right)}{\partial x_{j}}\right)$ in equation (2) is the Reynolds stresses term, in which the computational turbulence models for modeling the Reynolds stress are required to close the system of the Reynolds averaged equations.

To compute the water surface interface between air and water the Volume of fluid VOF method is applied as a multiphase model. In free surface flow some of these volumes are empty others are full with fluid and some are partial 
occupied by fluid, for this reason a percent of occupation between 0 and 1 is forwarded by researchers (Hirt and Nichols 1981 and Nikseresht et al. 2009). The equation (3) is used to define the percent of fluid in volumes:

$$
\frac{\partial \alpha_{w}}{\partial t}+u_{i} \frac{\partial \alpha_{w}}{\partial x_{i}}=0
$$

Where,

$\alpha_{w}$ : the volume fraction of water, $t$ : is time, and $u i$ : is the velocity in $x i$-direction.

The summations of the volume fractions of water and air is equal to unity, therefore the air volume fraction $\left(\alpha_{a}\right)$ can be computed by the equation:

$$
\alpha_{a}=1-\alpha_{w}
$$

According to the above equation each volumetric elements in domain can be defined as empty when $\alpha_{w}=0$, partially filled $0<\alpha_{w}<1$ and fill by fluid when $\alpha_{w}=1$.

In this study the analysis is performed in steady state and RNG $k-\varepsilon$ turbulence model was used that is derived from the Navier stokes equations by (Yakhot and Orszag 1986) which is based on the analysis of the renormalization group method to view the effect of the small scale turbulence in the Navier stokes equations and the improvement of the rapidly strain flow, transitional and separated flows. Furthermore, the high resolution advection scheme is used for mass and momentum for the purpose of accuracy in multiphase simulation, and the first order numeric scheme is applied for turbulence kinetic energy and dissipation rate.

\section{NUMERICAL SIMULATION}

\subsection{Model Geometry and Mesh Generation}

In the simulation process the first step was to generate the geometries of the flow region using ANSYS Design Modeler. The fluid domain geometry consisted of a 3D-rectangular horizontal open channel $5 \mathrm{~m}$ long, $0.45 \mathrm{~m}$ high and $0.3 \mathrm{~m}$ width with a model located inside the fluid domain in which the bottom right side corner of model was located at the origin point of the coordinate system. Eight models of Labyrinth stepped falls have been generated. The generated models have the same geometrical dimensions as those of the physical models which they tested in the laboratory flume, in which each model were constructed from $4 \mathrm{~mm}$ perspex plates. In these models the height was fixed to $0.25 \mathrm{~m}$, while two different downstream slopes were examined $(1 \mathrm{~V}: 1 \mathrm{H})$ and $(1 \mathrm{~V}: 2 \mathrm{H})$. Each of these models included 5 and 10 step numbers. The physical and numerical models of the labyrinth stepped falls were designed to have two different cycle widths. The cycle widths were $(0.06$ and $0.1 \mathrm{~m})$, and the number of runs for each model are fourteen varied between $(1$ to $12.794 \mathrm{l} / \mathrm{s})$ which was measured experimentally by the electromagnetic flow meter. The additional four plain stepped falls was generated with downstream slope $(1 \mathrm{~V}: 2 \mathrm{H}$ and $1 \mathrm{~V}: 1 \mathrm{H})$ and number of steps (5 and 10) for the purpose of comparison with labyrinth stepped falls as presented in Figure (1). The ANSYS Design Modeler was used for creating and generating geometry.

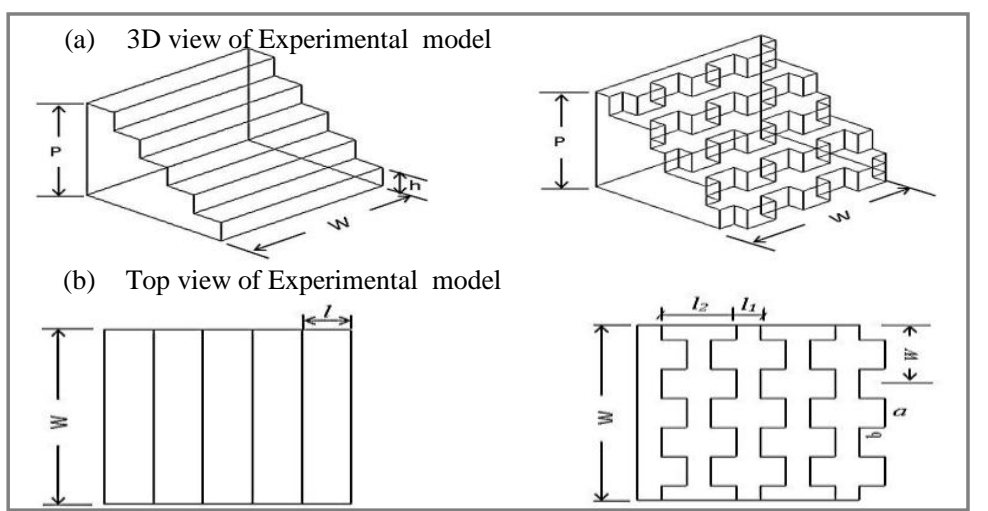

Fig. (1): Detailed view of Experimental model for plain and labyrinth stepped falls.

In this study, the multi-block structured format is used by dividing the domain of fluid into a number of blocks, for Labyrinth stepped falls is divided into five blocks as shown in Figure (2). The tetra mesh were used in the model region due to the complexity of fluid domain structure, while in the other four blocks the hexahedral mesh type were used. The Hybrids mesh is merged using pyramid mesh at interfaces which was generated 


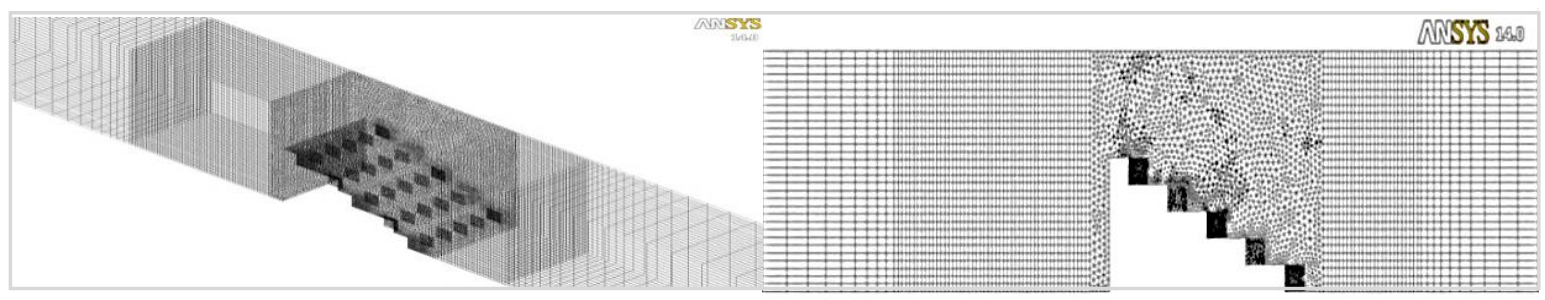

Fig. (2): 3D and typical view of mesh for Labyrinth stepped falls.

The fluid domain in the plain steps case is divided into three blocks. A multi-zone structured mesh type was used by selecting hexa type for mapped mesh surface with a mixture of hexa and widges elements for free element type as presented in Figure (3). The total number of elements used for plain stepped falls is (208325252495).

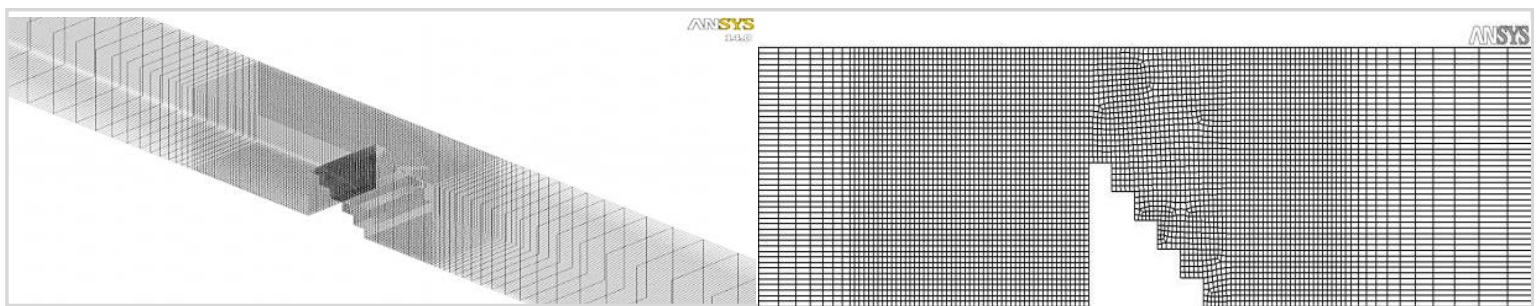

Fig. (3): 3D and typical view of mesh for plain stepped falls.

In general finer mesh sizes are required at places that due to rapid variation of the properties of flow. For this purpose, mesh adaption is applied which is one of the important process in which the mesh is automatically refined during the simulation calculation (ANSYS-CFX help 2014) as shown in Figure (4). The total number of elements for Labyrinth and plain stepped falls after generating mesh adaption are (19213692865147) and (774147-1554131).

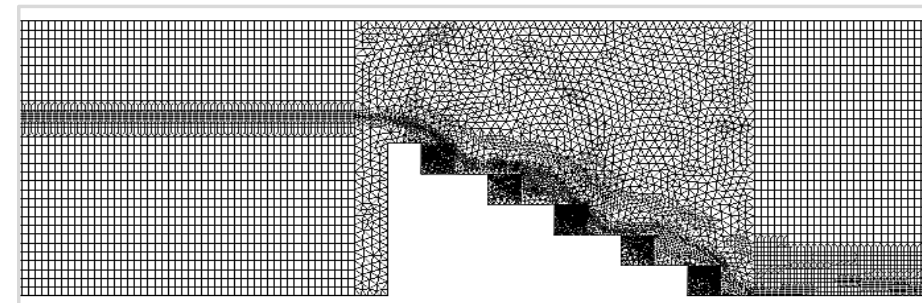

Fig. (4): Mesh adaption (finer mesh at water surface).

\subsection{Boundary and Initial Conditions}

Boundary conditions are applied for fluid domain to all surfaces as those in physical model, flow rate at the inlet, pressure at the outlet boundary. The three other surfaces of domain (front, back and bottom) are defined as smooth walls with non-slip boundary condition. The top surface is defined as opening with entrainment and zero relative pressure, this definition specifies the free surface flow conditions. Figure (5) shows these conditions. Initialization values are velocity components, upstream pressure, upstream volume fraction of water and air at the inlet. 


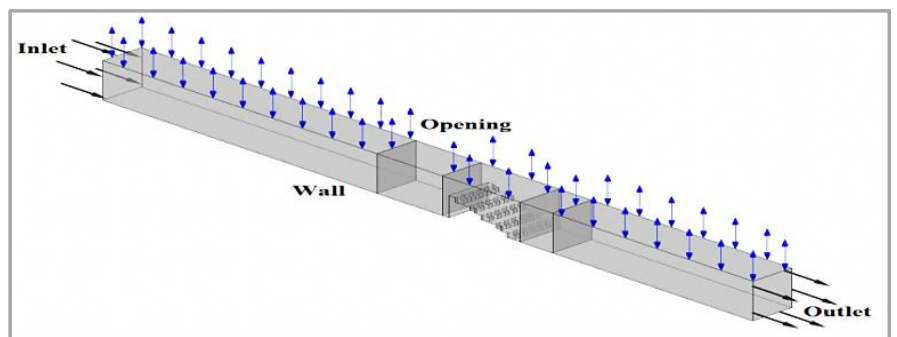

Figure (5): Specified boundary conditions used for this study.

\section{VERIFICATION OF NUMERICAL MODEL IN ANSYS CFX SOFTWARE}

In this study ANSYS CFX package was adopted to simulate the flow field variables on stepped falls. Numerical models were generated and tested using the same geometries and flow conditions of those used in the experimental models. The numerical model was verified by comparing the computational results predicted by numerical models with the experimental results in terms of position of free surface, hydraulic head and amount of energy dissipation rates. Then, the verified model was used to study the velocity flow variable on stepped falls.

\subsection{Water Surface Profile}

The experimental measurements for the water surface profile which were measured using a point gauge with an accuracy of $0.1 \mathrm{~mm}$ and the numerical output of the simulations are compared. In which the water surface profile were recorded at the centerline and at a distance equal to the half cycle width from the centerline of each model. The comparison for 168 runs is based on mean absolute percentage error (MAPE). The MAPE is defined in equation (5), which is the most common scale-independent relative measure for determining errors as a percentage from the actual data, it provides an easy way of measuring errors (Myttenaere, et.al. 2015).

$$
M A P E=\frac{100}{m} \sum_{i=1}^{m}\left|\frac{\text { Observed }- \text { Predicted }}{\text { Predicted }}\right|
$$

The minimum and maximum values of mean absolute percentage error for all models is $0.28 \%$ and $2.89 \%$ for labyrinth steps, while the error for plain stepped falls is between $0.32 \%$ and $2.26 \%$. This comparison shows an acceptable agreement between simulated water surface profile and the measured values along the flow. This agreement points out that the numerical model was efficient in detecting the position of surface profile over stepped falls. Figures (6) to (11) illustrate a number of runs conducted on experimental models and captured on the numerical models. The comparisons between them are also shown. Figure (6) shows that the water falls from one labyrinth step to another in a series of plunges with the appearance of air bubble entrainment. This flow characteristic means that a nappe flow regime is developed. This regime type has been observed and shown in plate on Figure (6). The nappe flow regime over plain stepped falls is illustrated on Figure (7). Figures (8) and (9) illustrates that the transition flow occurs in the shape of small air cavity and splashing near the free surface. From Figures (10) and (11) it can be seen that the water falls as a coherent stream with intense recirculation vortices in between step edges which is the main feature of skimming flow regime.

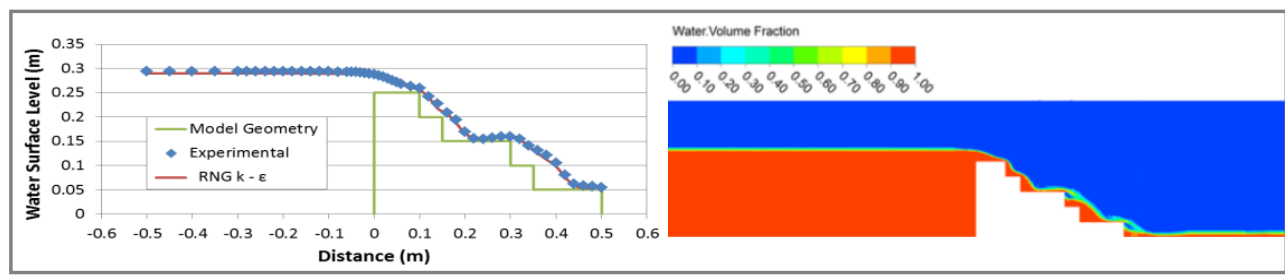

(a) Water surface profile comparison at centerline of the model 


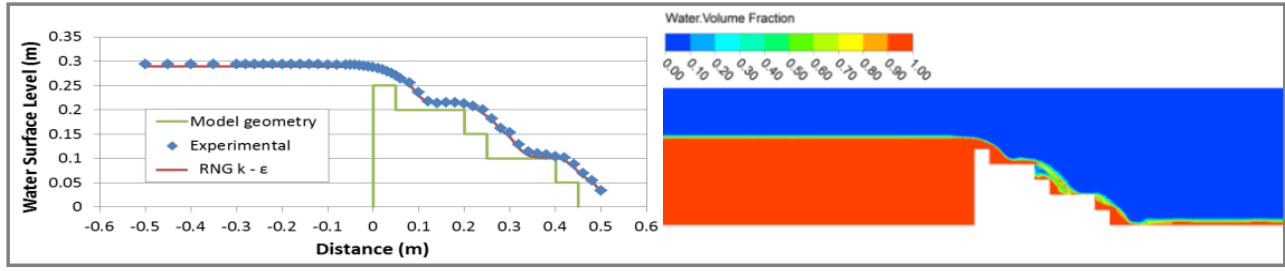

(b) Water surface profile comparison at $3 \mathrm{~cm}$ from centerline of the model

(c)

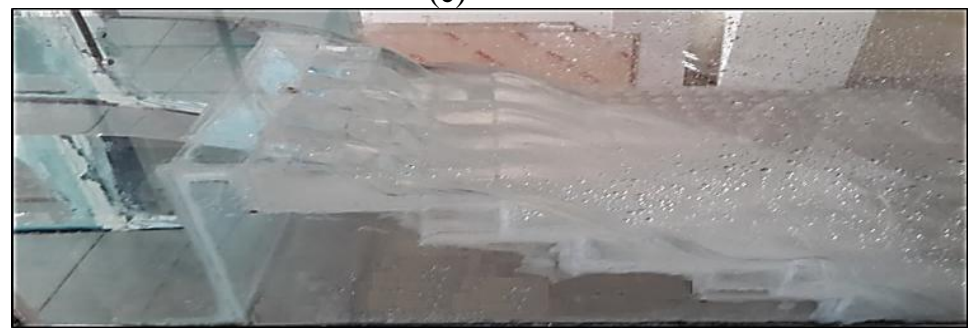

(d) Photo of water surface profile of physical model

(e)

Fig. (6): Nappe flow water surface profile of the Labyrinth stepped falls for $(\mathrm{N}=5, \mathrm{~S}=1 / 2, \mathrm{w}=6 \mathrm{~cm}$ and $\mathrm{Q}=3.973 \mathrm{l} / \mathrm{s})$.

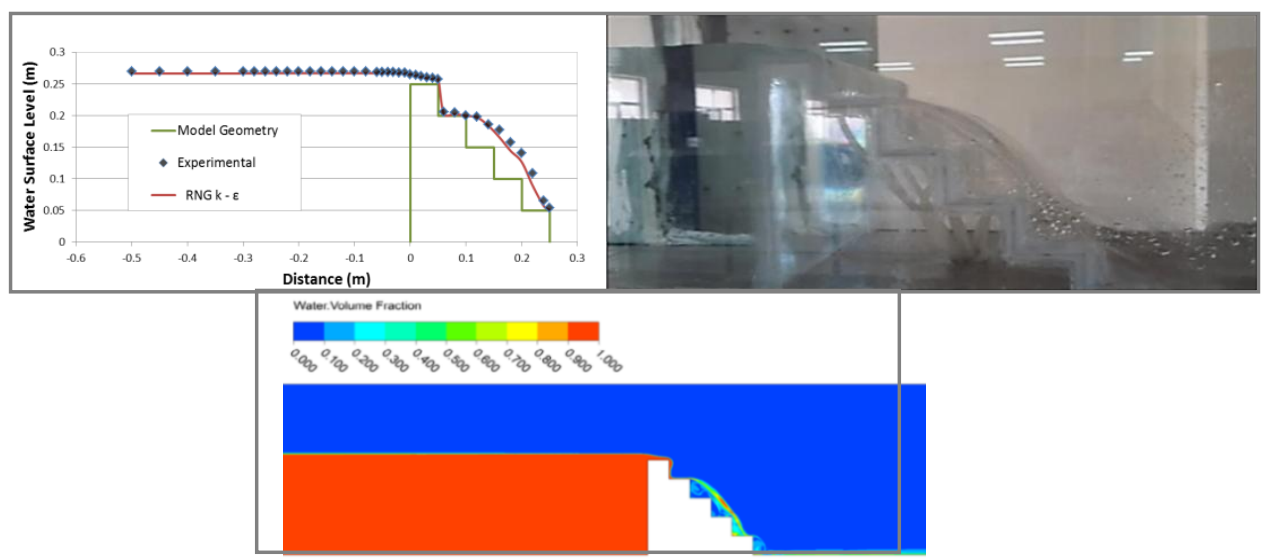

Figure (7): Nappe flow water surface profile comparison on the plain stepped falls for $(\mathrm{N}=5, \mathrm{~S}=1$ and $\mathrm{Q}=1 \mathrm{l} / \mathrm{s})$.

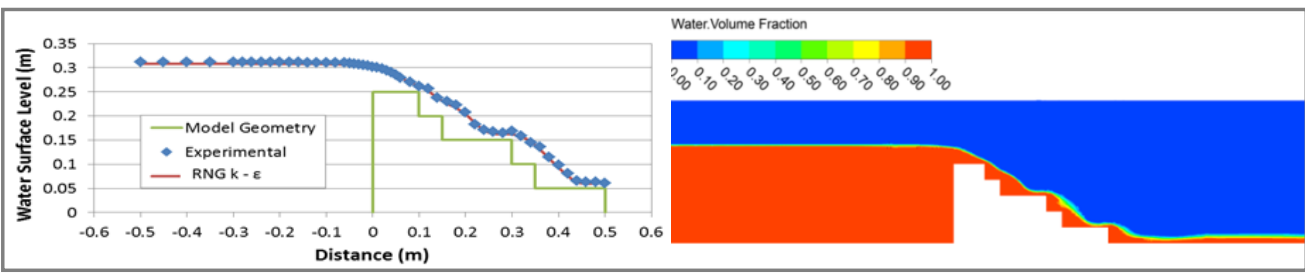

(a) Water surface profile comparison at centerline of the model

(b)

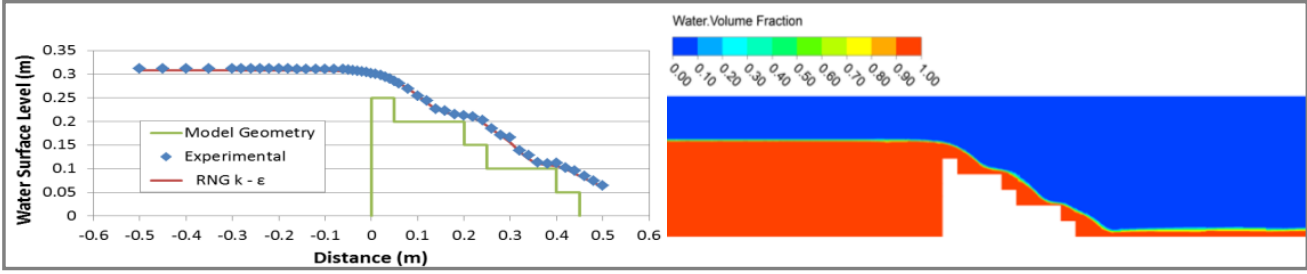

(c) Water surface profile comparison at $3 \mathrm{~cm}$ from centerline of the model

(d) 


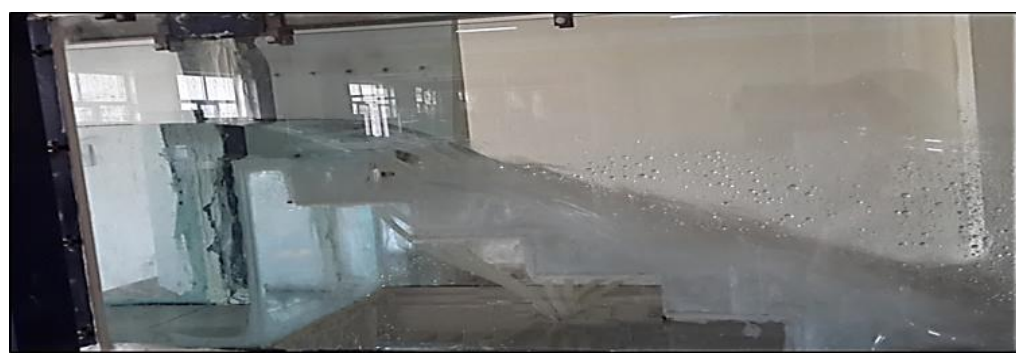

(e) Photo of water surface profile of physical model

Fig. (8): Transition flow water surface profile of the Labyrinth stepped falls for $(\mathrm{N}=5, \mathrm{~S}=1 / 2$, $w=6 \mathrm{~cm}$ and $\mathrm{Q}=7.51$ $1 / \mathrm{s})$.

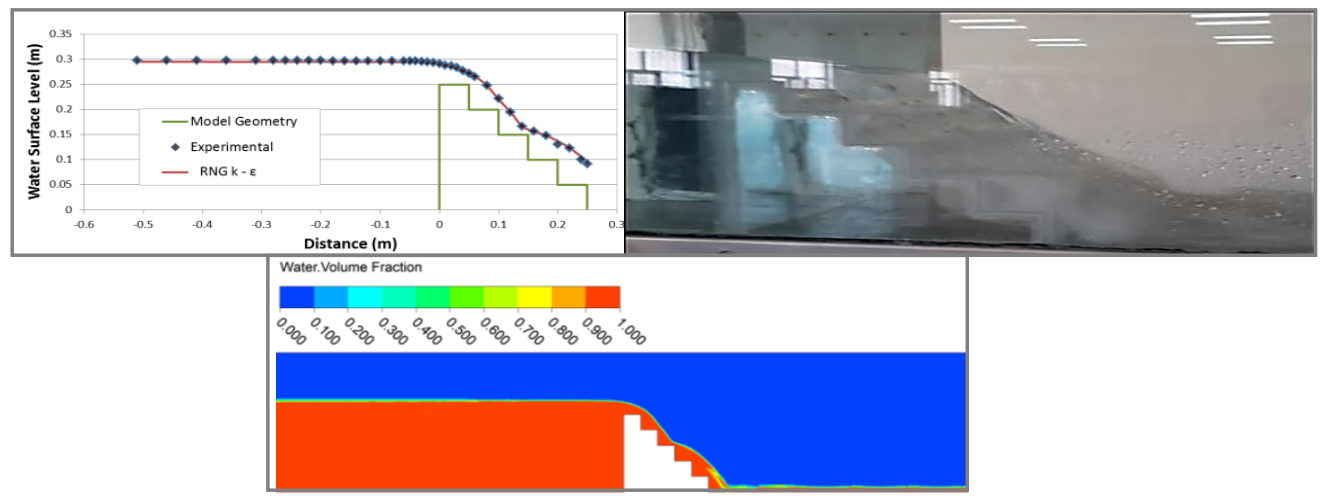

Fig.(9): Transition flow water surface profile comparison on the plain stepped falls for $(\mathrm{N}=5, \mathrm{~S}=1$ and $\mathrm{Q}=4.984 \mathrm{l} / \mathrm{s})$.

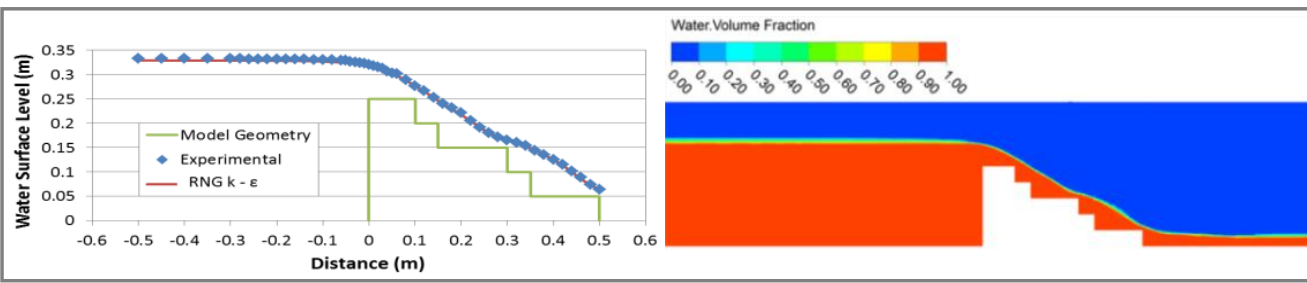

(a) Water surface profile comparison at centerline of the model

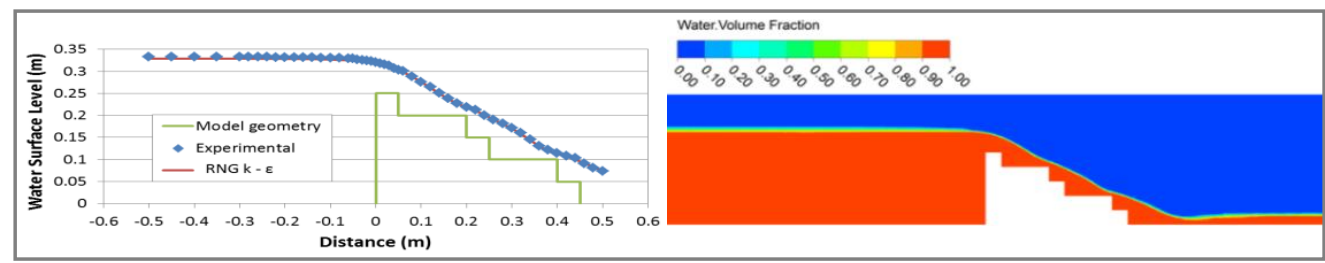

(b) Water surface profile comparison at $3 \mathrm{~cm}$ from centerline of the model

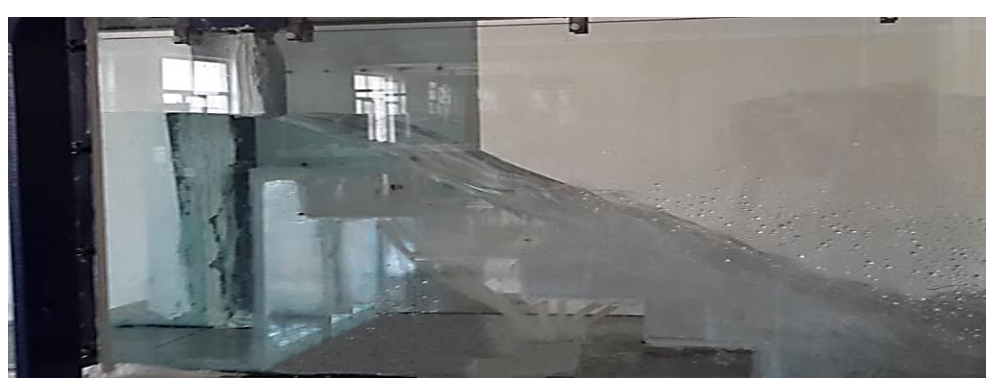

(c) Photo of water surface profile of physical model

Fig. (10): Skimming flow water surface profile of the Labyrinth stepped falls for $(\mathrm{N}=5, \mathrm{~S}=1 / 2, \mathrm{w}=6 \mathrm{~cm}$ and $\mathrm{Q}=12.58 \mathrm{l} / \mathrm{s})$. 


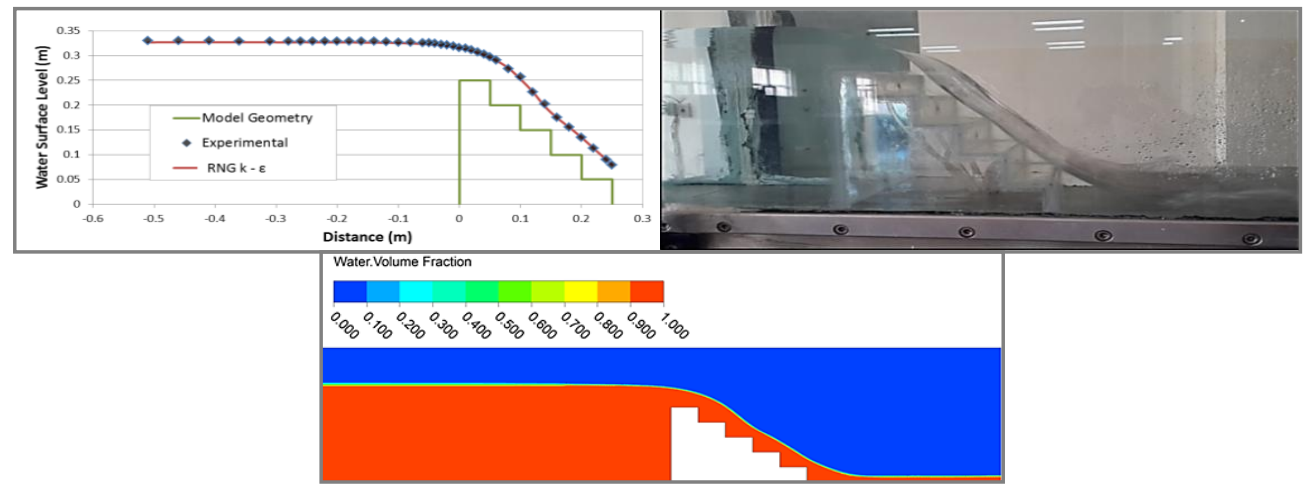

Fig. (11): Skimming flow water surface profile comparison on the plain stepped falls for ( $N=5, S=1$ and $Q=12.651 / s)$.

\subsection{Hydraulic Head Results on Horizontal and Vertical Steps}

The hydraulic head (pressure distribution) was measured in the laboratory by means of piezometers at the middle of certain vertical and horizontal step faces in all models (labyrinth and plain stepped falls). The hydraulic head from the outputs of simulation is selected at the same locations as those measured in laboratory. The variation of hydraulic head along the length of the falls is illustrated in Figure (12) and Figure (13) for labyrinth step face and for plain step face respectively. These figures show that the hydraulic head readings are close for the experimental and numerical models, with some differences at some places due to the high turbulent fluctuations in flow.
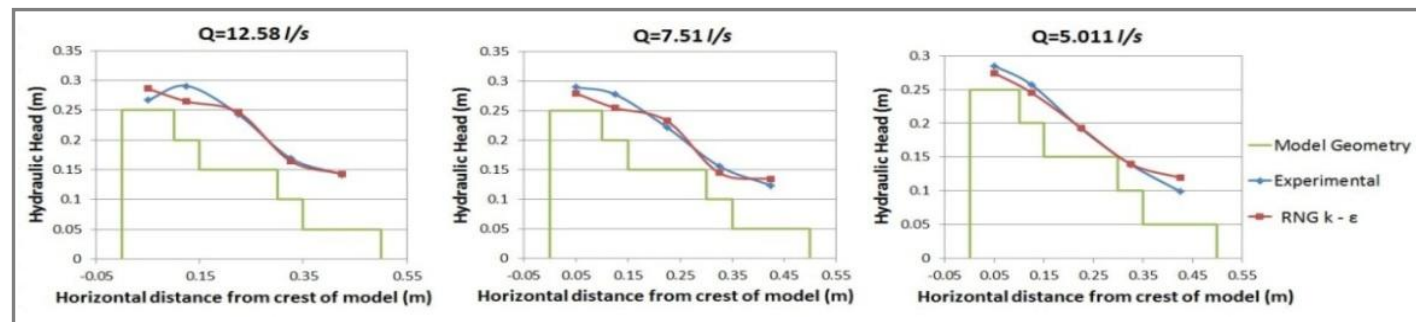

Fig. (12): Comparison between experimental and numerical values of hydraulic head on horizontal step faces for $(\mathrm{N}=5, \mathrm{~S}=1 / 2$ and $\mathrm{w}=6 \mathrm{~cm})$.
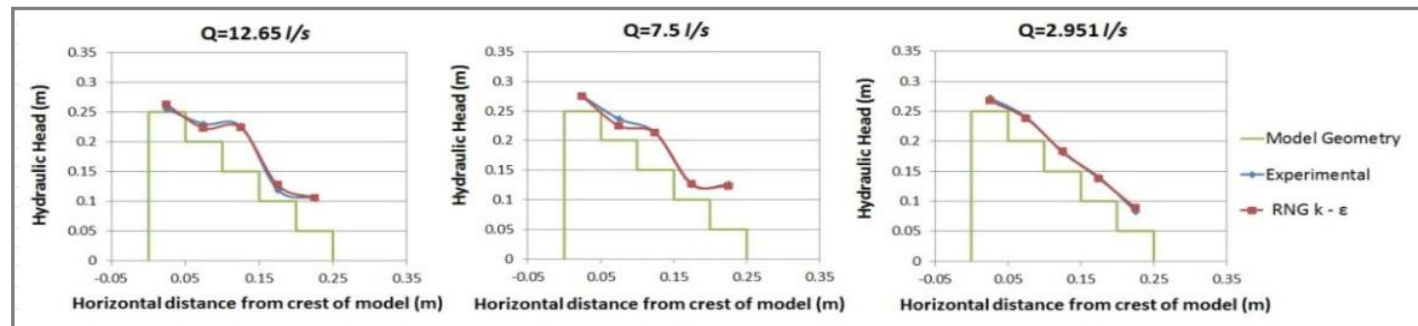

Fig. (13):- Comparison between experimental and numerical values of hydraulic head on horizontal step faces for $(\mathrm{N}=5$ and $\mathrm{S}=1 / 1)$.

To test the accuracy of agreement of hydraulic head results of experimental and numerical models on horizontal step faces of labyrinth and plain stepped falls, a t-test was carried out to test the difference between means of two independent groups. The statistical results showed that the Levene's test $F$ value for both labyrinth and plain steps is (0.657 and 0.009) and its significance (p) is (0.418 and 0.924) respectively, which is greater than alpha $(0.05)$ which means the variance is homogenous and it is significantly acceptable. Also it can be noted that for confidence $95 \%$ the lower and upper values contains zero which indicates the test rejected the null hypothesis and the test is accepted at alpha equal 0.05 as listed in table (1) and table (2). Moreover the determination coefficient $\mathrm{R}^{2}$ between experimental and numerical results in terms of the hydraulic head is 0.969 and 0.968 for labyrinth and plain steps respectively which means good agreement. 
Table (1): Independent samples test for horizontal labyrinth steps

\begin{tabular}{|c|c|c|c|c|c|c|c|c|c|}
\hline \multirow[t]{3}{*}{ Hydraulic head } & \multicolumn{2}{|c|}{$\begin{array}{l}\text { Levene's Test } \\
\text { for Equality of } \\
\text { Variances }\end{array}$} & \multicolumn{7}{|c|}{ t-test for Equality of Means } \\
\hline & \multirow[t]{2}{*}{$F$} & \multirow[t]{2}{*}{ Sig. } & \multirow[t]{2}{*}{$t$} & \multirow[t]{2}{*}{ df } & \multirow[t]{2}{*}{$\begin{array}{l}\text { Sig. (2- } \\
\text { tailed) }\end{array}$} & \multirow[t]{2}{*}{$\begin{array}{c}\text { Mean } \\
\text { Difference }\end{array}$} & \multirow[t]{2}{*}{$\begin{array}{l}\text { Std. Error } \\
\text { Difference }\end{array}$} & \multicolumn{2}{|c|}{$\begin{array}{l}95 \% \text { Confidence Interval } \\
\text { of the Difference }\end{array}$} \\
\hline & & & & & & & & Lower & Upper \\
\hline $\begin{array}{l}\text { Equal } \\
\text { variances } \\
\text { assumed }\end{array}$ & .657 & .418 & 1.266 & 1110 & .206 & .005008 & .003954 & -.002751 & .012767 \\
\hline $\begin{array}{l}\text { Equal } \\
\text { variances not } \\
\text { assumed }\end{array}$ & & & 1.266 & 1109.022 & .206 & .005008 & .003954 & -.002751 & .012767 \\
\hline
\end{tabular}

Table (2): Independent samples test for horizontal plain steps

\begin{tabular}{|c|c|c|c|c|c|c|c|c|c|}
\hline \multirow[t]{3}{*}{$\begin{array}{l}\text { Hydraulic } \\
\text { head }\end{array}$} & \multicolumn{2}{|c|}{$\begin{array}{l}\text { Levene's Test for } \\
\text { Equality of } \\
\text { Variances }\end{array}$} & \multicolumn{7}{|c|}{ t-test for Equality of Means } \\
\hline & \multirow[t]{2}{*}{$F$} & \multirow[t]{2}{*}{ Sig. } & \multirow[t]{2}{*}{$t$} & \multirow[t]{2}{*}{ df } & \multirow[t]{2}{*}{$\begin{array}{l}\text { Sig. (2- } \\
\text { tailed) }\end{array}$} & \multirow[t]{2}{*}{$\begin{array}{c}\text { Mean } \\
\text { Difference }\end{array}$} & \multirow[t]{2}{*}{$\begin{array}{l}\text { Std. Error } \\
\text { Difference }\end{array}$} & \multicolumn{2}{|c|}{$\begin{array}{c}95 \% \text { Confidence Interval } \\
\text { of the Difference }\end{array}$} \\
\hline & & & & & & & & Lower & Upper \\
\hline $\begin{array}{l}\text { Equal } \\
\text { variances } \\
\text { assumed }\end{array}$ & .009 & .924 & .296 & 236 & .768 & .0025067 & .0084761 & -.0141918 & .0192053 \\
\hline $\begin{array}{l}\text { Equal } \\
\text { variances } \\
\text { not assumed }\end{array}$ & & & .296 & 235.844 & .768 & .0025067 & .0084761 & -.0141919 & .0192053 \\
\hline
\end{tabular}

The variation of hydraulic head on vertical surface of step and along the whole length of falls is illustrated in Figure (14) and Figure (15) for labyrinth step face and for plain step face respectively. These figures show the trend of head variation along the steps, even in some locations there are some discrepancies of hydraulic head readings between experimental and numerical models, and this is expected because of the presentation of high circulating velocity at vertical faces at some locations causing a build up negative pressure and air cavity in these regions. The negative pressure readings are difficult to measure experimentally. In spite of that there is reasonable agreement between the experimental and numerical results.

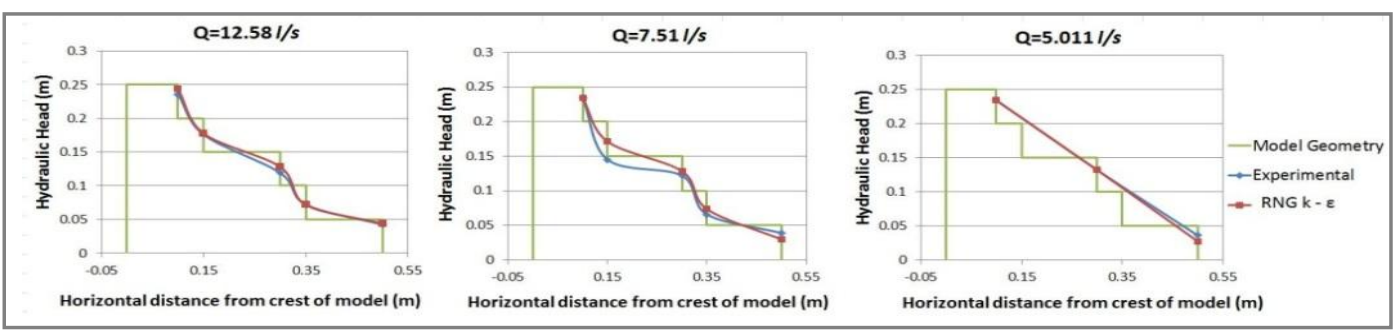

Fig. (14): Comparison between experimental and numerical values of Hydraulic head on vertical step faces for $(\mathrm{N}=5, \mathrm{~S}=1 / 2$ and

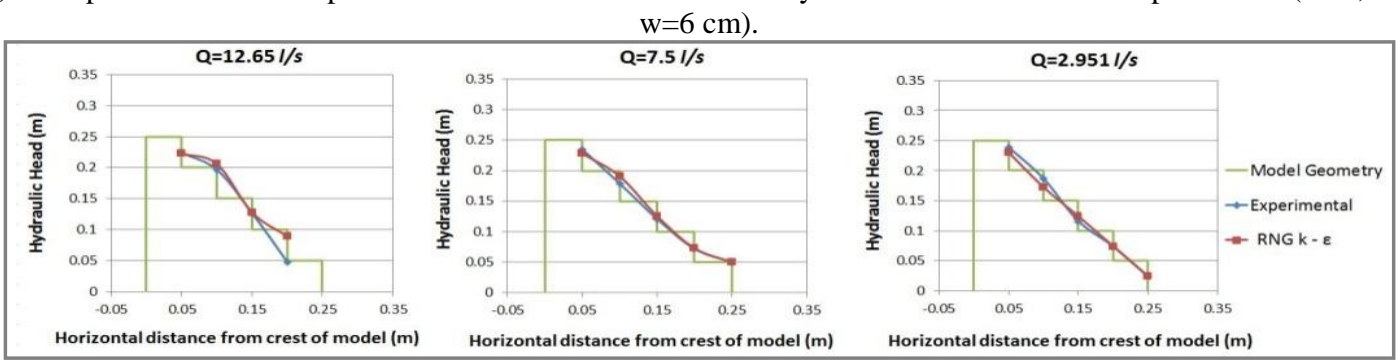

Fig. (15): Comparison between experimental and numerical values of hydraulic head on vertical step faces for $(\mathrm{N}=5$ and $\mathrm{S}=1)$.

The agreement between experimental and numerical models has been tested by t-test which shows that Levene's test $\mathrm{F}$ for both labyrinth and plain steps is (1.159 and 0.034$)$ and its significance is $(0.282$ and 0.853$)$ respectively which is greater than alpha $(0.05)$ and it is significantly acceptable and means that the variance is homogeneous and there are no differences between the two mean values. In addition, for confidence $95 \%$ the zero is available 
between the lower and upper intervals. This means the null hypothesis is rejected and the test is acceptable at alpha equal 0.05 , as listed in table (3) and table (4). Moreover the determination coefficient $\mathrm{R}^{2}$ between experimental and numerical hydraulic head results is 0.847 and 0.973 for labyrinth and plain steps respectively which means good agreement.

Table (3): Independent samples test for vertical labyrinth steps

\begin{tabular}{|c|c|c|c|c|c|c|c|c|c|}
\hline \multirow[t]{3}{*}{$\begin{array}{l}\text { Hydraulic } \\
\text { head }\end{array}$} & \multicolumn{2}{|c|}{$\begin{array}{l}\text { Levene's Test } \\
\text { for Equality of } \\
\text { Variances }\end{array}$} & \multicolumn{7}{|c|}{ t-test for Equality of Means } \\
\hline & \multirow[t]{2}{*}{$F$} & \multirow[t]{2}{*}{ Sig. } & \multirow[t]{2}{*}{ t } & \multirow[t]{2}{*}{ df } & \multirow[t]{2}{*}{$\begin{array}{l}\text { Sig. (2- } \\
\text { tailed) }\end{array}$} & \multirow[t]{2}{*}{$\begin{array}{c}\text { Mean } \\
\text { Difference }\end{array}$} & \multirow[t]{2}{*}{$\begin{array}{l}\text { Std. Error } \\
\text { Difference }\end{array}$} & \multicolumn{2}{|c|}{$\begin{array}{l}\text { 95\% Confidence } \\
\text { Interval of the } \\
\text { Difference }\end{array}$} \\
\hline & & & & & & & & Lower & Upper \\
\hline $\begin{array}{l}\text { Equal } \\
\text { variances } \\
\text { assumed }\end{array}$ & 1.159 & .282 & -1.413 & 816 & .158 & -.0069094 & .0048910 & -.0165099 & .0026910 \\
\hline $\begin{array}{l}\text { Equal } \\
\text { variances not } \\
\text { assumed }\end{array}$ & & & -1.413 & 813.919 & .158 & -.0069094 & .0048910 & -.0165099 & .0026911 \\
\hline
\end{tabular}

Table (4): Independent samples test for vertical plain steps

\begin{tabular}{|c|c|c|c|c|c|c|c|c|c|}
\hline \multirow[t]{3}{*}{$\begin{array}{l}\text { Hydraulic } \\
\text { Head }\end{array}$} & \multicolumn{2}{|c|}{$\begin{array}{c}\text { Levene's Test } \\
\text { for Equality of } \\
\text { Variances }\end{array}$} & \multicolumn{7}{|c|}{ t-test for Equality of Means } \\
\hline & \multirow[t]{2}{*}{$F$} & \multirow[t]{2}{*}{ Sig. } & \multirow[t]{2}{*}{$\mathbf{t}$} & \multirow[t]{2}{*}{ df } & \multirow[t]{2}{*}{$\begin{array}{l}\text { Sig. (2- } \\
\text { tailed) }\end{array}$} & \multirow[t]{2}{*}{$\begin{array}{c}\text { Mean } \\
\text { Difference }\end{array}$} & \multirow[t]{2}{*}{$\begin{array}{l}\text { Std. Error } \\
\text { Difference }\end{array}$} & \multicolumn{2}{|c|}{$\begin{array}{l}95 \% \text { Confidence Interva } \\
\text { of the Difference }\end{array}$} \\
\hline & & & & & & & & Lower & Upper \\
\hline $\begin{array}{l}\text { Equal } \\
\text { variances } \\
\text { assumed }\end{array}$ & .034 & .853 & -.074 & 254 & .941 & -.0006539 & .0088517 & -.0180860 & .0167782 \\
\hline
\end{tabular}

\subsection{Energy Dissipation Rate}

The percentage of energy dissipation means the relation between the differences of water energy at the upstream and the downstream of model structure to the energy of water at the upstream of model structure. The comparison shows good agreement between the experimental and numerical results for all labyrinth and plain stepped fall models with the percentage error ranging from $(0.03 \%$ to $6.35 \%)$ and $(0.13 \%$ to $5.03 \%)$ respectively. These results reveal that the numerical model efficiently predicted the flow field variables on stepped falls as qualitative and quantitative agreements have been achieved compared with the experimental results.

The relation between energy dissipation and discharge for both experimental and numerical results is illustrated in Figure (16) which shows that the energy dissipation is increased with decrease of discharge, moreover the labyrinth steps cause more energy dissipation that plain steps because of increasing the total length of labyrinth.

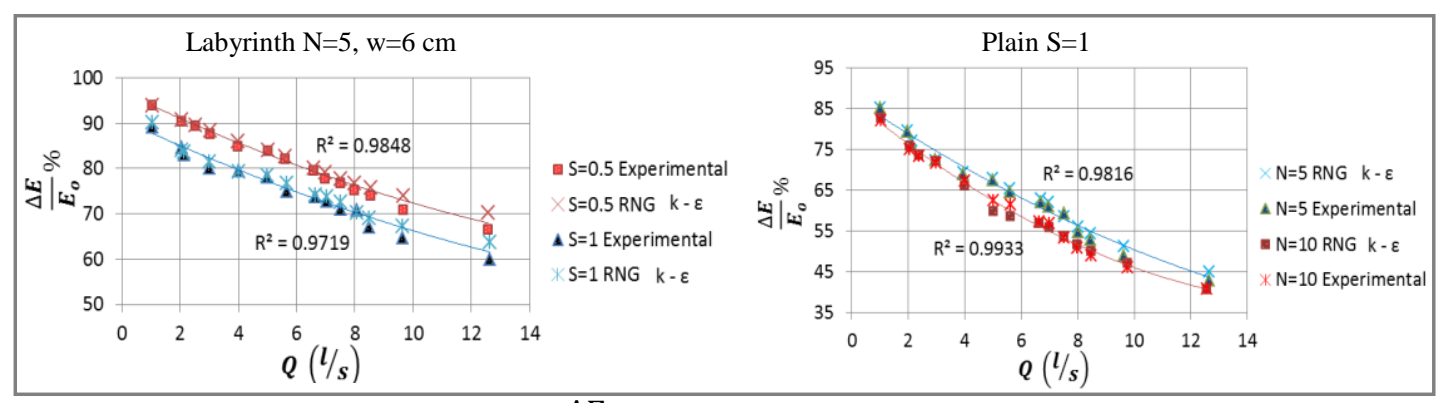

Fig. (16): Variation of ( $\left.\Delta E / E_{0} \%\right)$ with ( $\mathrm{Q}$ ) for labyrinth stepped falls. 
It is worth mentioning here that numerical output results of RNG $\mathrm{k}-\varepsilon$ model allow to get deeper vision for the structure of flow to understand different between the quantity of energy dissipated in both type of falls. This can also leads understand the effect of the width of the labyrinth cycle on the amount of dissipated energy. For this purpose velocity vector and streamlines are plotted in Figures (17) to (30) for both labyrinth and plain stepped falls. From these figures it can be seen that water flows in different directions over labyrinth stepped falls. Each step in labyrinth stepped fall consists of plain rectangles. This combination (zigzag) causes local changes in the direction of flow. The directions of flow depend on the depth of water on the steps and the width of the labyrinth cycle. Also the interaction and interference in the directions of flow caused by flow falling over three sides of rectangular labyrinth cycles cause an increase in the rate of energy dissipation. Furthermore, the energy dissipation increases with increasing length magnification ratio due to increasing impingement angle of the water velocity vectors flowing over labyrinth stepped falls as illustrated in Figures (22) to (25). The average impinging angles were (74 and 62.5 degree) for the length magnification ratios (1.83 and 1.5) respectively.

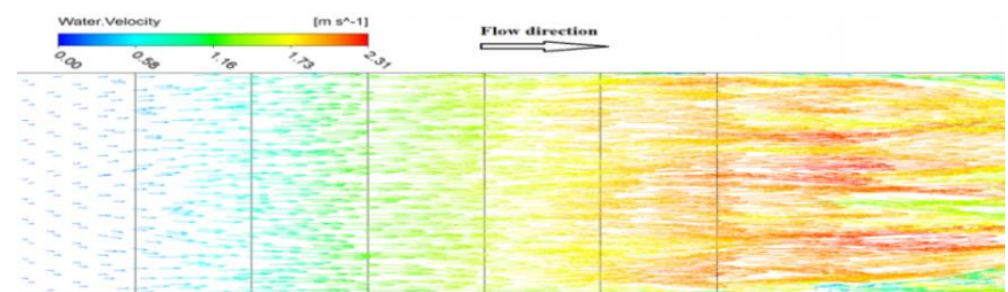

Fig.(17): Water velocity vectors for plain stepped falls of $(N=5, S=1 / 2$ and $Q=4.981 / s)$.

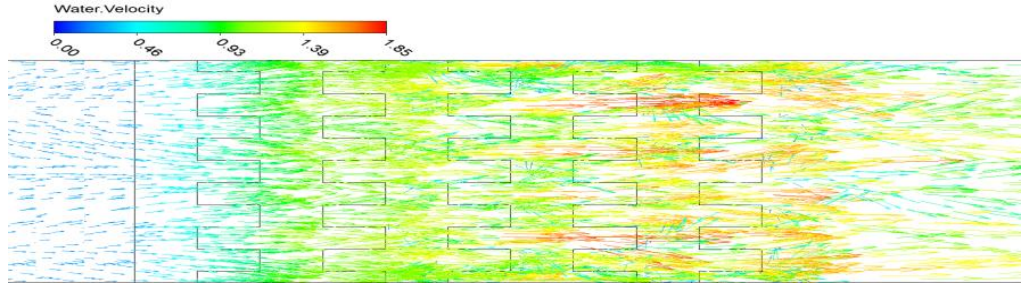

Fig. (18): Water velocity vectors for labyrinth stepped falls of $(\mathrm{N}=5, \mathrm{~S}=1 / 2, \mathrm{w}=6 \mathrm{~cm}$ and $\mathrm{Q}=5.011 \mathrm{l} / \mathrm{s})$.

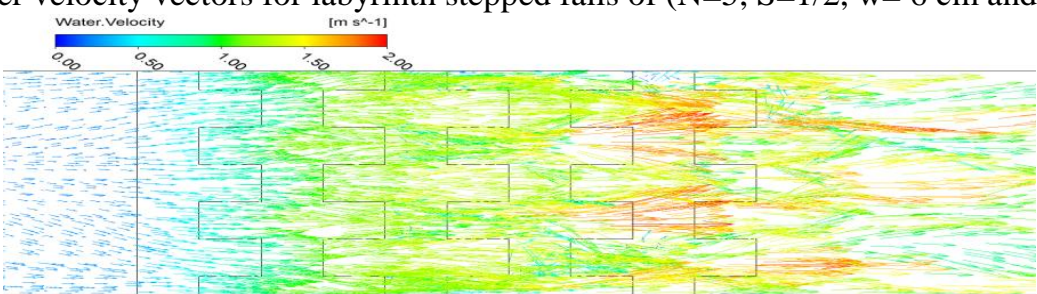

Fig.(19): Water velocity vectors for labyrinth stepped falls of $(\mathrm{N}=5, \mathrm{~S}=1 / 2, \mathrm{w}=10 \mathrm{~cm}$ and $\mathrm{Q}=4.94 \mathrm{l} / \mathrm{s})$.

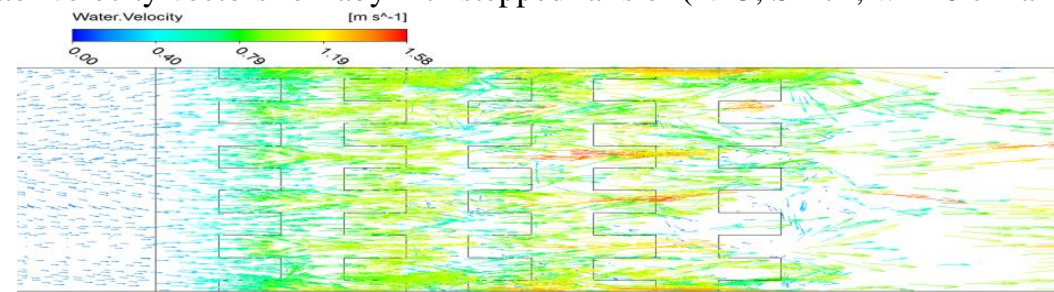

Fig. (20): Water velocity vectors for labyrinth stepped falls of $(\mathrm{N}=5, \mathrm{~S}=1 / 2, \mathrm{w}=6 \mathrm{~cm}$ and $\mathrm{Q}=2.05 \mathrm{l} / \mathrm{s})$.

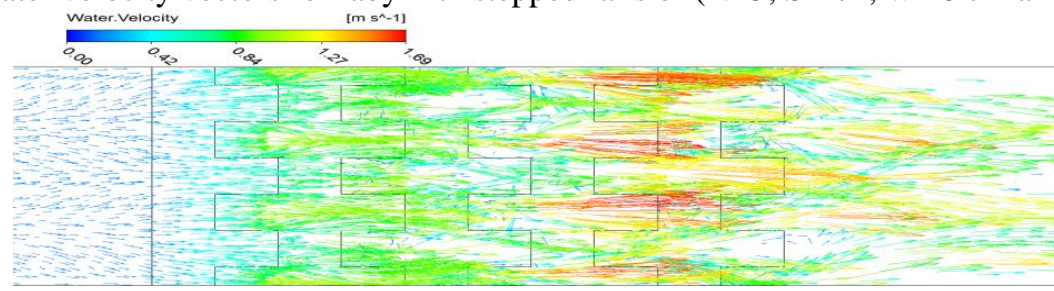

Fig. (21): Water velocity vectors for labyrinth stepped falls of $(\mathrm{N}=5, \mathrm{~S}=1 / 2, \mathrm{w}=10 \mathrm{~cm}$ and $\mathrm{Q}=2.038 \mathrm{l} / \mathrm{s})$. 

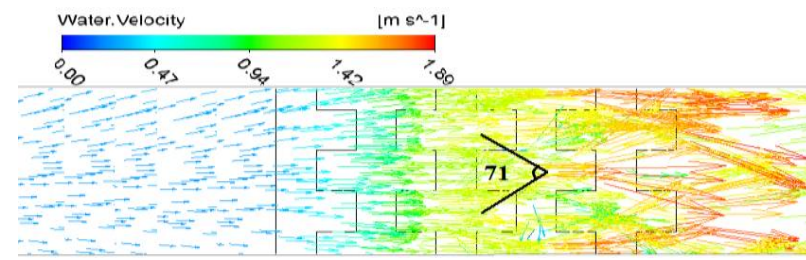

Fig.(22): Water velocity vectors for labyrinth stepped falls of $(\mathrm{N}=5, \mathrm{~S}=1, \mathrm{w}=6 \mathrm{~cm}$ and $\mathrm{Q}=3.997 \mathrm{l} / \mathrm{s})$.

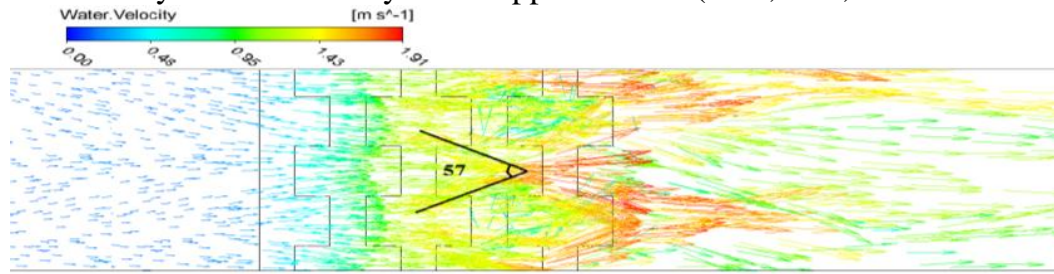

Fig. (23): Water velocity vectors for labyrinth stepped falls of $(\mathrm{N}=5, \mathrm{~S}=1, \mathrm{w}=10 \mathrm{~cm}$ and $\mathrm{Q}=3.973 \mathrm{l} / \mathrm{s})$.

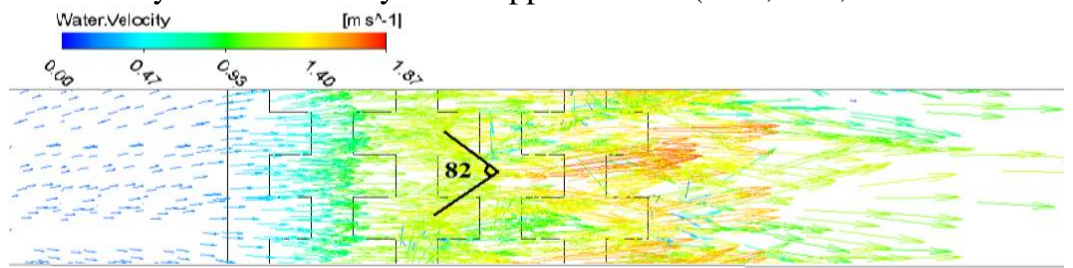

Fig. (24): Water velocity vectors for labyrinth stepped falls of $(\mathrm{N}=5, \mathrm{~S}=1, \mathrm{w}=6 \mathrm{~cm}$ and $\mathrm{Q}=3.01 \mathrm{l} / \mathrm{s})$.

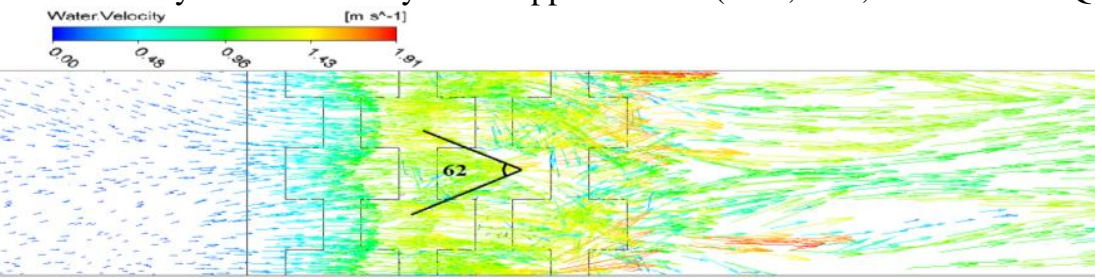

Fig. (25): Water velocity vectors for labyrinth stepped falls of $(\mathrm{N}=5, \mathrm{~S}=1, \mathrm{w}=10 \mathrm{~cm}$ and $\mathrm{Q}=3.01 \mathrm{l} / \mathrm{s})$.

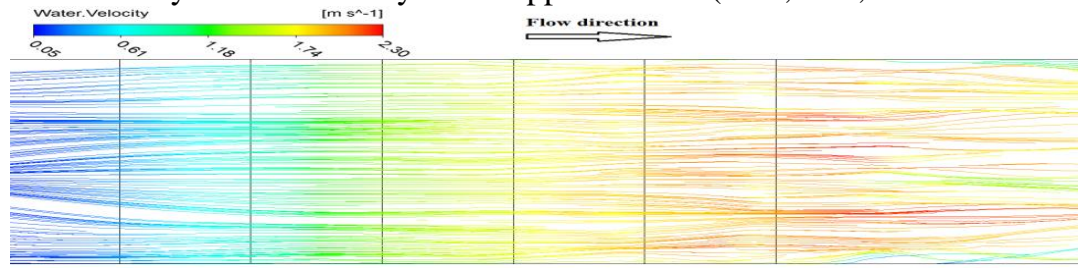

Fig. (26): Water velocity streamlines for plain stepped falls of $(N=5, S=1 / 2$ and $Q=4.981 / s)$.

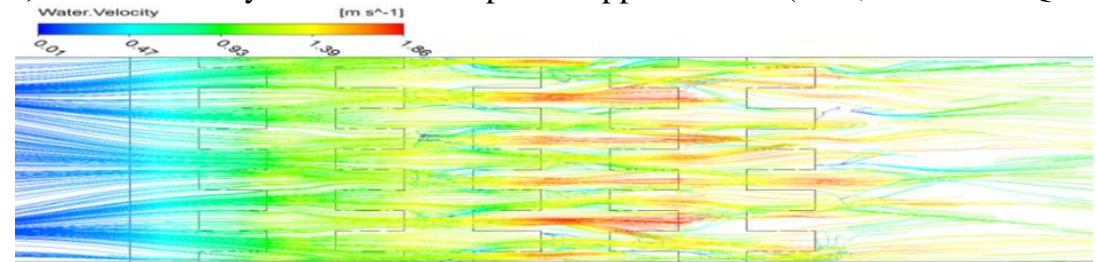

Fig. (27): Water velocity streamlines for labyrinth stepped falls of $(\mathrm{N}=5, \mathrm{~S}=1 / 2, \mathrm{w}=6 \mathrm{~cm}$ and $\mathrm{Q}=5.011 \mathrm{l} / \mathrm{s})$.

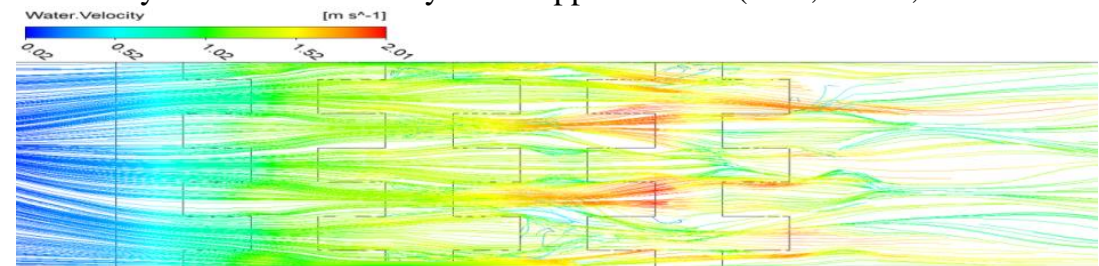

Fig. (28): Water velocity streamlines for labyrinth stepped falls of $(\mathrm{N}=5, \mathrm{~S}=1 / 2, \mathrm{w}=10 \mathrm{~cm}$ and $\mathrm{Q}=4.94 \mathrm{l} / \mathrm{s})$. 


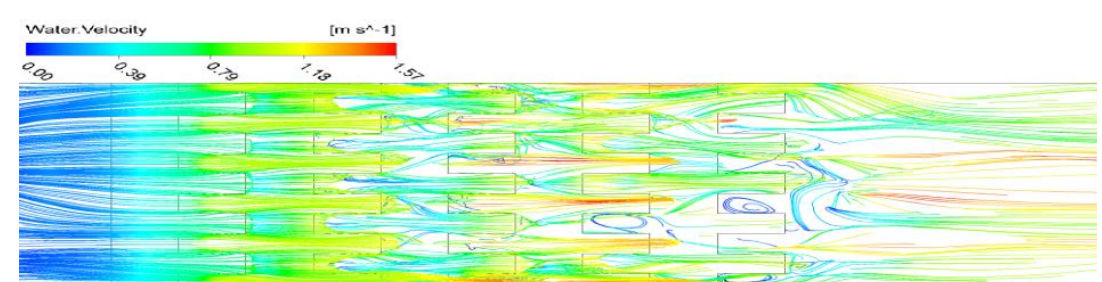

Fig. (29): Water velocity streamlines for labyrinth stepped falls of $(\mathrm{N}=5, \mathrm{~S}=1 / 2, \mathrm{w}=6 \mathrm{~cm}$ and $\mathrm{Q}=2.05 \mathrm{l} / \mathrm{s})$.

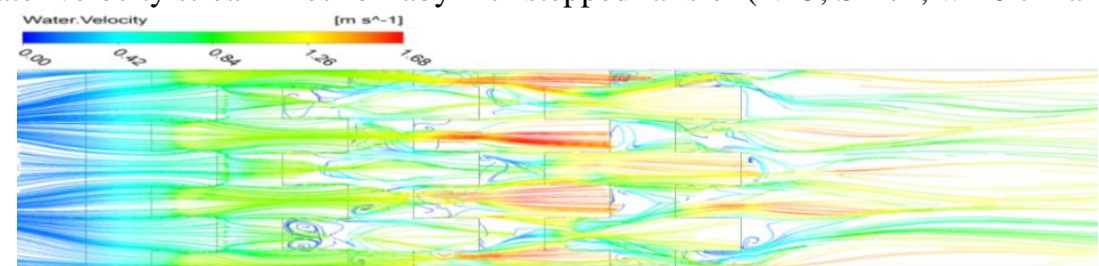

Fig. (30): Water velocity streamlines for labyrinth stepped falls of $(\mathrm{N}=5, \mathrm{~S}=1 / 2, \mathrm{w}=10 \mathrm{~cm}$ and $\mathrm{Q}=2.0381 / \mathrm{s})$.

\section{Velocity Distribution on Steps}

The water velocity distribution in the flow domain is an important character to explain flow structure. The variation in its value in three crosssection planes provide better understanding for the flow regimes and the differences in energy dissipation to show some main visualizations of velocity distribution contours, illustrations are presented in Figures (31) to (33) for the horizontal plane in model region. Evidently the velocity increases in direction of flow as the potential energy changes to kinetic, but the maximum value is occurs on plain steps. The plain stepped fall has higher velocity with an average about $14 \%$ compared to labyrinth for same discharge; this means that kinetic energy at the downstream is higher (less energy dissipation), also the maximum value of velocity happens at the last steps of the plain type, while it happens nearly upper location on the labyrinth falls. Moreover the labyrinth of $\mathrm{w}=10$ (wider cycle) have higher value of maximum velocity.

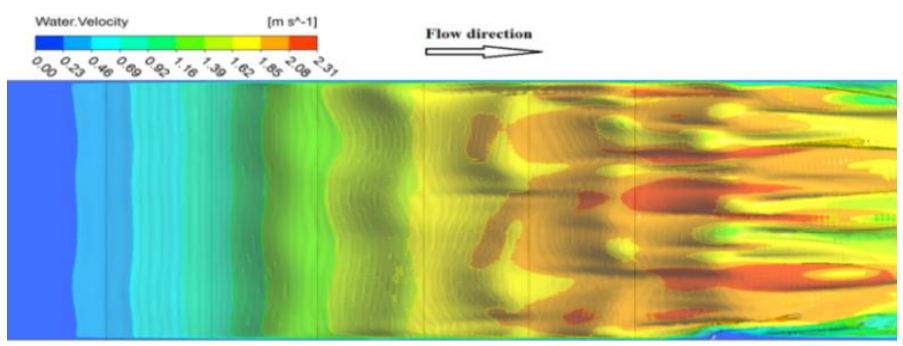

Fig. (31): Plan of water velocity contours for plain stepped falls of $(\mathrm{N}=5, \mathrm{~S}=1 / 2$ and $\mathrm{Q}=4.98 \mathrm{l} / \mathrm{s})$.

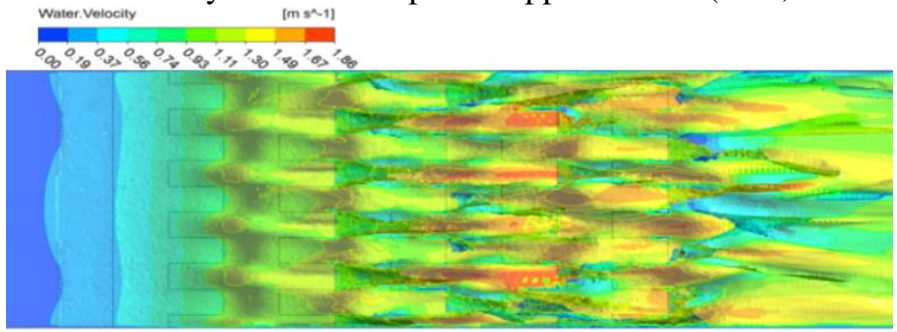

Fig. (32): Plan of water velocity contours for labyrinth stepped falls of $(\mathrm{N}=5, \mathrm{~S}=1 / 2, \mathrm{w}=6 \mathrm{~cm}$ and $\mathrm{Q}=5.011 \mathrm{l} / \mathrm{s})$.

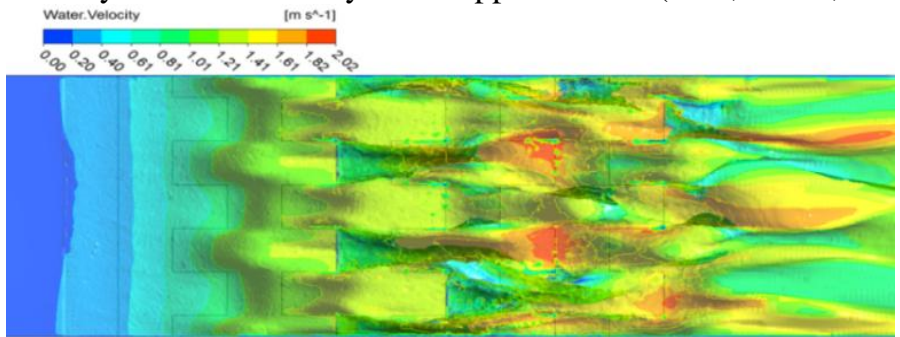

Fig. (33): Plan of water velocity contours for labyrinth stepped falls of $(\mathrm{N}=5, \mathrm{~S}=1 / 2, \mathrm{w}=10 \mathrm{~cm}$ and $\mathrm{Q}=4.94 \mathrm{l} / \mathrm{s})$. 
The velocity distributions along the longitudinal plane cross-section are visualized and illustrated in Figures (34) to (36). These illustrations shows the changes in values of the velocity and its maximum value on the plain steps

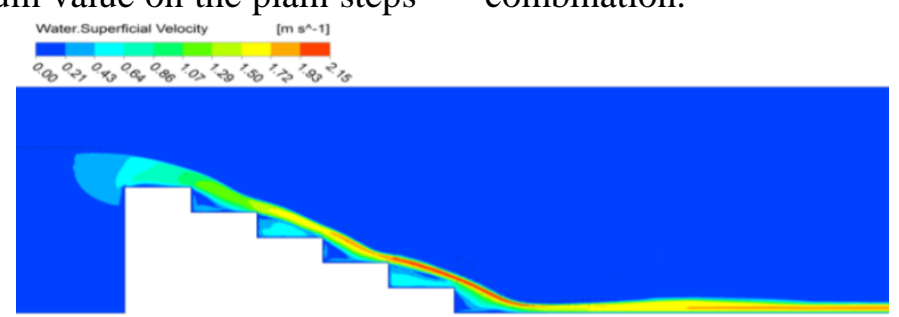

Fig. (34): Profile of water velocity contours for plain stepped falls of $(\mathrm{N}=5, \mathrm{~S}=1 / 2$ and $\mathrm{Q}=9.562 \mathrm{l} / \mathrm{s})$.

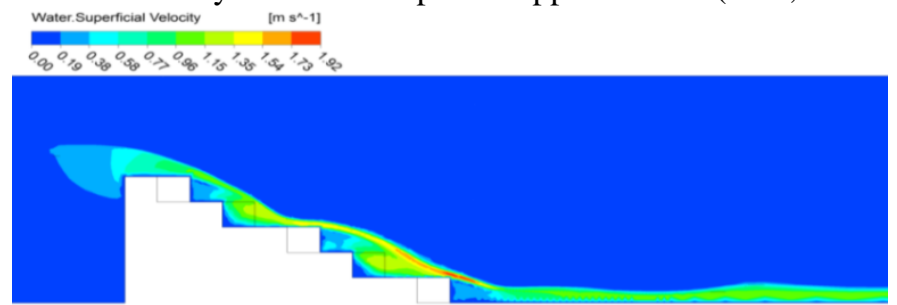

Fig. (35): Profile of water velocity contours for labyrinth stepped falls of $(\mathrm{N}=5, \mathrm{~S}=1 / 2, \mathrm{w}=10 \mathrm{~cm}$ and $\mathrm{Q}=9.631 \mathrm{l} / \mathrm{s})$.

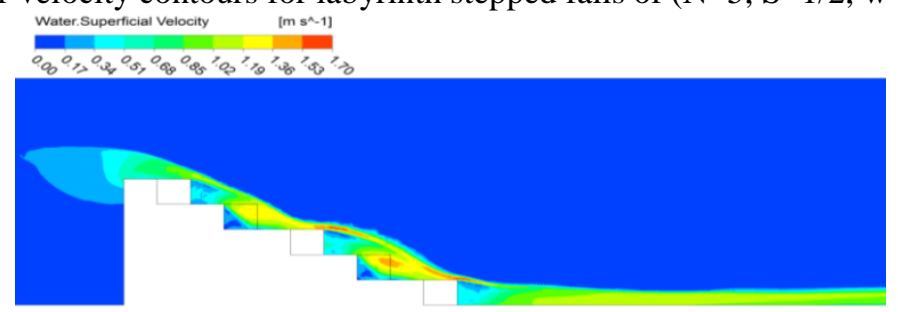

Fig. (36): Profile of water velocity contours for labyrinth stepped falls of $(\mathrm{N}=5, \mathrm{~S}=1 / 2, \mathrm{w}=6 \mathrm{~cm}$ and $\mathrm{Q}=9.67 \mathrm{l} / \mathrm{s})$.

To understand the effect of zigzag and its width cycle (gape) on the distribution of velocity, cross-section planes have been taken in the perpendicular direction to the flow, which are illustrated in Figure (37). The illustrations have been done on each step and for the two different width of cycle ( $\mathrm{w}=6 \mathrm{~cm}$ and $\mathrm{w}=10 \mathrm{~cm})$. This figure shows that water velocity increase towards the free surface of flow, and illustrate that the higher velocity contours also concentrated between the zigzag gape. 


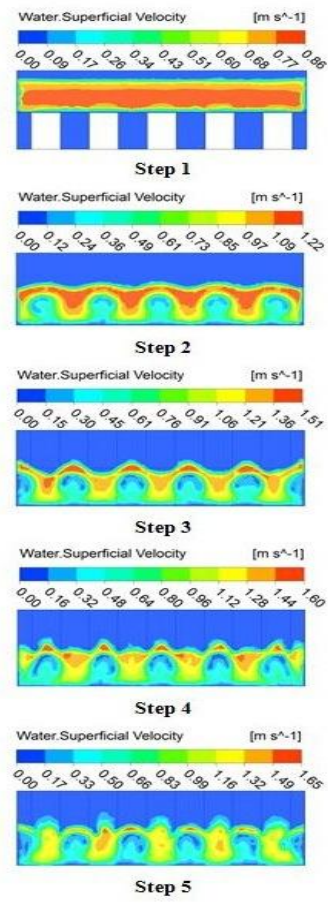

(a) Cycle width $\mathrm{w}=6 \mathrm{~cm}$

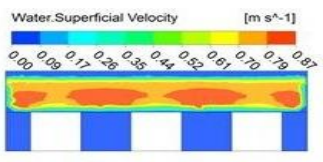

Step 1

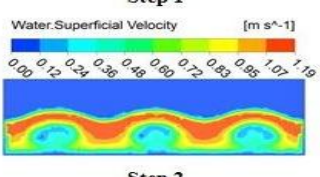

Step 2

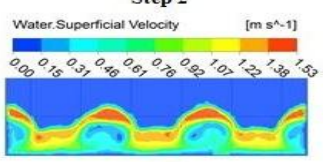

Step 3

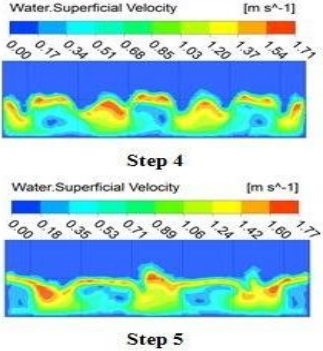

(b) Cycle width $\mathrm{w}=10 \mathrm{~cm}$

Fig. (37): Water velocity contours at center of steps in yz-plane for labyrinth stepped model of $(N=5, S=1 / 2$ and $\mathrm{Q}=9.65 \mathrm{l} / \mathrm{s})$.

As it was observed and documented through the laboratory experimental work that there are three types of flow regimes, the simulation out puts visualized these regimes. Figures (38) and (39) present velocity vectors of skimming and nappe flow regimes respectively. The nappe flow regime looks like flow on series of weirs, it can be
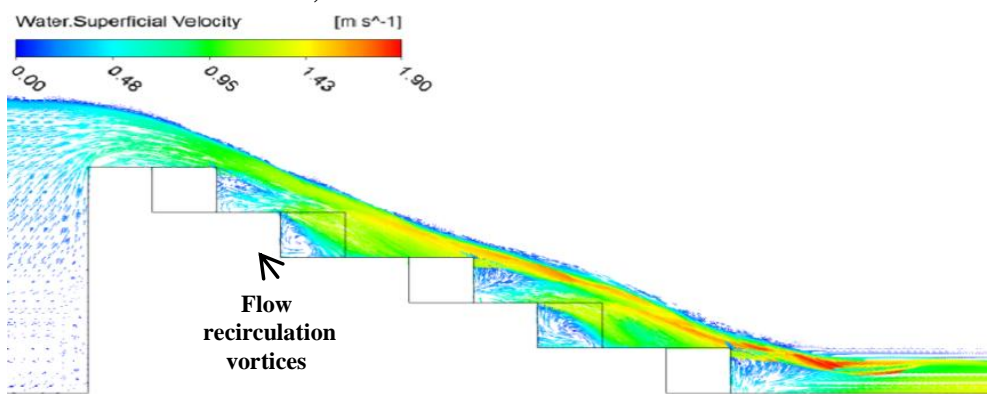

Fig.(38): Skimming water velocity vectors for $(\mathrm{N}=5, \mathrm{~S}=1 / 2, \mathrm{w}=10 \mathrm{~cm}$ and $\mathrm{Q}=12.57 \mathrm{l} / \mathrm{s})$.

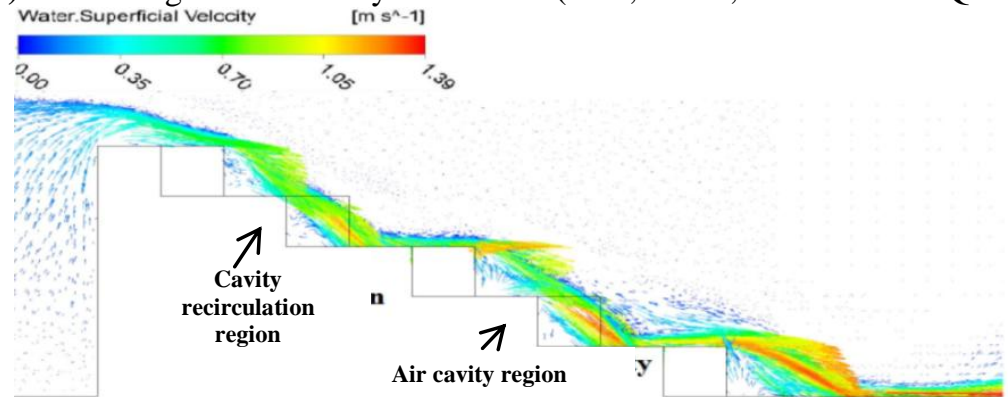

Fig. (39): Nappe water velocity vectors for $(\mathrm{N}=5, \mathrm{~S}=1 / 2, \mathrm{w}=10 \mathrm{~cm}$ and $\mathrm{Q}=4.94 \mathrm{1} / \mathrm{s})$. 
The model geometry and flow rate are the main factors affecting on the percentage of dissipated energy, the formation of flow regime and the location of separation point. These effects are reflected on the flow structure. To take a general look at the changes in velocity profiles, the labyrinth model of five steps and a slope of $1 \mathrm{~V}: 2 \mathrm{H}$ is chosen. The average velocity values at certain depths of flow are found from numerical model. These velocities are illustrated in Figures (40) to (42) for two different discharges and two labyrinth cycle lengths on two different steps (step No. 2 and No. 5). It can be seen from Figure (40) that the velocity distribution consists of two parts. The first part is adjacent to the step surface, which has relatively small thickness and has nearly linear increase in velocity (viscous layer). The velocity distribution at the center of steps has a curve shape of power relationship on the highest steps. This trend changes on the lowest steps according to the flow type. It can be noted that on the center of step 5 the velocity distribution has a shape of S-curve. This indicates that the separation zone is generated. Also these figures show that the value of velocity profile sharply increases with the depth at the edge of step before falling to the next step. At the edge of step, when the water begins to chute freely, the second portion of velocity distribution becomes also nearly linear shape with a steep increase in velocity on the lower steps. All these changes in velocity reflected on the momentum of the microelements.

Figures (41) and (42) shows that the cycle length affects the velocity profile. The velocity has a little bit higher value on the center of upper step for narrow labyrinth and in an opposite manner and steeper at the step edge. In addition, it shows that the thickness of skimming depth is less for wider labyrinth cycle.

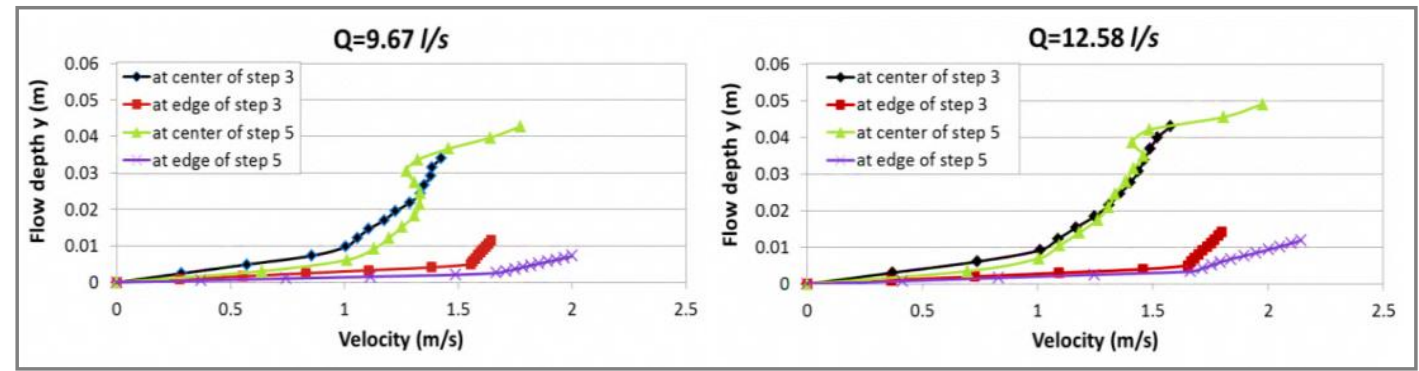

Figure (40): Velocity profiles for labyrinth model of $(\mathrm{N}=5, \mathrm{~S}=1 / 2, \mathrm{w}=6 \mathrm{~cm})$.

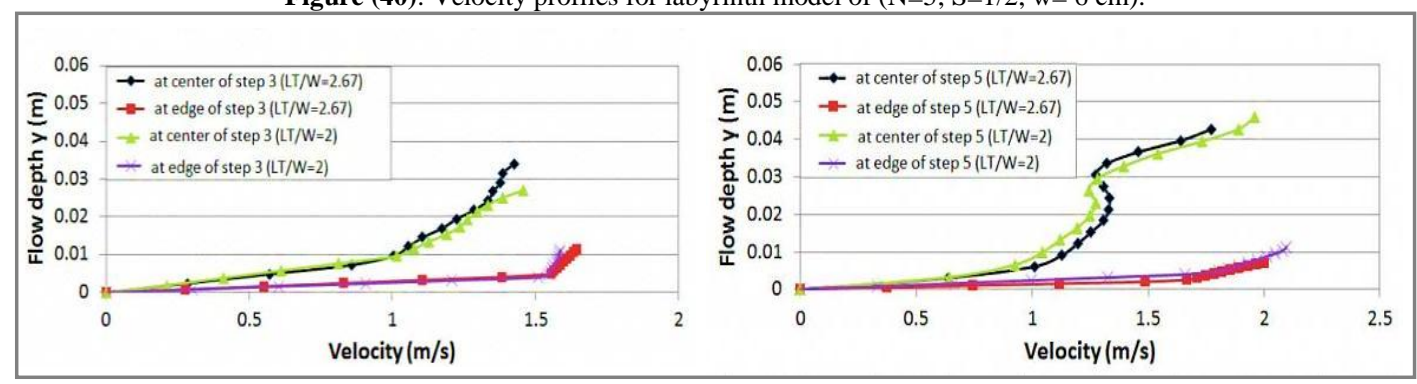

Figure (41): Velocity profiles for labyrinth model of $(\mathrm{N}=5, \mathrm{~S}=1 / 2$ and $\mathrm{Q}=9.65 \mathrm{l} / \mathrm{s})$

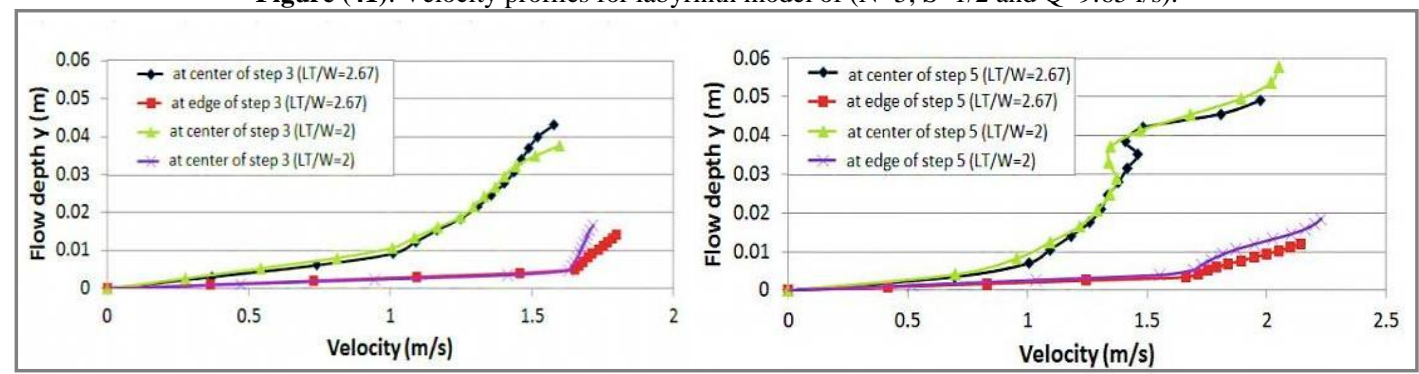

Figure (42): Velocity profiles for labyrinth model of $(\mathrm{N}=5, \mathrm{~S}=1 / 2$ and $\mathrm{Q}=12.58 \mathrm{l} / \mathrm{s})$. 


\section{CONCLUSIONS}

Within the limitations of the present study the following findings and conclusions can be drawn: 1. The comparison of water surface profile between experimental models and RNG $\mathrm{k}-\varepsilon$ numerical model indicates good agreement. Mean absolute percentage error for plain and labyrinth stepped falls ranges from (0.32 to $2.26 \%)$ and (0.28 to $2.89 \%)$ respectively.

2. The turbulent RNG $\mathrm{k}-\varepsilon$ model simulate hydraulic head results on certain horizontal and vertical step faces and shows acceptable agreement compared to measured values for both plain and labyrinth stepped falls.

3. The energy dissipation comparison shows good agreement between the experimental and numerical results. The minimum and maximum percentage error for plain and labyrinth stepped falls ranges from (0.19 to 5.03\%) and (0.03 to $6.35 \%)$ respectively.

4. The results are correctly represents reality which proof that the system is valid for simulation. The ANSYS CFX numerical model using the RNG $\mathrm{k}-\varepsilon$ turbulence model with VOF method is capable of simulating complex flow over labyrinth stepped fall models.

5. The finer mesh at the model region by using the mesh adaption is very important for multiphase flow problems.

6. Labyrinth stepped fall shows higher ability to dissipate energy than the plain stepped fall for the same hydraulic conditions.

\section{REFERENCES}

Ameen, A. S. (2014). Modeling the Flow over Stepped Spillway using Computational Fluid Dynamics, M.Sc. Thesis, University of Tikrit, Iraq.

ANSYS-CFX Help, Release14.0, (2011): http://www.ANSYS.com.

Bazargan, J. and Safakheil M. (2013). Influence of Slope and the Number of Steps on Energy Dissipation in Stepped Spillway using Numerical Model, Journal of Water Sciences Research, Vol. 4, No. 1, pp. (57-69).
Carvalho, R.F. and Martins, R. (2009). Stepped Spillway with Hydraulic Jumps, Application of a Numerical Model to a Scale Model of a Conceptual Prototype, Journal of Hydraulic Engineering, Vol. 135, No. 7, pp. (615-619).

Chanson H, Toombes L. (2001). Experimental Investigations of Air Entrainment in Transition and Skimming Flows down a Stepped Chute, Application to Embankment over Flow Stepped Spillways. Research Report No. CE158, Department of Civil Engineering, University of Queensland, Brisbane, Australia. 77pp.

Chen, Q., Dai, G. and Liu, H. (2002). Volume of Fluid Model for Turbulence Numerical Simulation of Stepped Spillway Overflow, Journal of Hydraulic Engineering, Vol. 128, No. 7, pp. (683-688).

Hirt, C.W. and Nichols, B.D. (1981). Volume of Fluid (VOF) Method for the Dynamics of Free Boundaries, Journal of Computational Physics, Vol. 39, No. 1, pp. (201-225).

Husain, S.M., Muhammed, J.R., Karunarathna, H.U. and Reeve, D.E. (2014). Investigation of Pressure Variations over Stepped Spillways using Smooth Particle Hydrodynamics, Advances in Water Resources, 66, pp. (52-69).

Jahromi, H.M., Bina, M. and Salmasi, F. (2008). Studied Physical and Numerical Modeling of the Nappe Flow in the Stepped Spillways, Journal of Applied Science, Vol. 8, No. 9, pp. (17201725).

Jorabloo, M. and Fuladipanah, M. (2013). A Survey on Dissipation Energy in a Stepped Spillway combined with Stilling Basin Step using Fluent Numerical Model, Journal of Applied Science and Agriculture, Vol. 8, No. 7, pp. (1059-1064).

Karami, S. P., Khosrojerdi, A. and Bajestan, M. S. (2014). Numerical Modelling of Hydraulic Flow in Dam Stepped Spillway and Study of Cavitation Phenomenon, European Online Journal of Natural and Social Sciences, Vol. 3, No. 3, pp. (283-294).

Kositgittiwong, D. (2012). Validation of Numerical Model of the Flow behavior through Smooth 
and Stepped Spillways using Large-scale Physical Model, Ph.D. Thesis, Faculty of Engineering, King Mongkut's University of Technology, Thonburi.

Nikseresht, A.H., Alishahi, M.M. and Emdad, H. (2009). Generalized Curvilinear Coordinate Interface Tracking in the Computational Domain, Scientia Iranica. Transaction B: Mechanical Engineering, Vol. 16, No. 1, pp. (64-74).

Piradeepan, N. (2002). An Experimental and Numerical Investigation of a Turbulent Airfoil Wake in a $90^{\circ}$ Curved Duct, Ph.D. Thesis, Department of Mechanic Engineering, Brunel University.

Rad, I.N. and Teimouri, M. (2010). An Investigation of Flow Energy Dissipation in Simple Stepped Spillways by Numerical Model, European Journal of Scientific Research, Vol. 47, No. 4, pp. (544-553).

Salmasi, F. (2003). Hydraulic Investigation and Physical Modeling on Stepped Spillways, Ph.D thesis, Shahid Chamran University, Ahvaz, Iran.

Shoja, F., Nikpour, M. R. and Sadeghi, H. (2013). Determination of Energy Dissipation in Stepped Spillways using Finite Element and Finite Volume Methods, Journal of Civil Engineering and Urbanism, Vol. 3, No. 4, pp. (150-155).

Taghizadeh, H., Neyshabour, S.A.A.S. and Ghasemzadeh, F. (2012). Dynamic Pressure Fluctuations in Stepped Three-Side Spillway, Iranica Journal of Energy and Environment, Vol. 3, No. 2, pp. (95-104).

Ward, J.P. (2002). Hydraulic Design of Stepped Spillways, Doctor of Philosophy dissertation, Civil Engineering, Faculty of Engineering, Colorado State University, USA.

Yakhot, V. and Orszag, S.A. (1986). Renormalization Group Analysis of Turbulence, Journal of Sci. Comput., Vol. 1, No. 3. 